\title{
Day case angioplasty in a secondary care setting - initial experience
}

\author{
Alexander Rodway ${ }^{1,4}$, Michelle Stafford ${ }^{1,5}$, Sophie Wilding ${ }^{1,2}$, Nikolaos Ntagiantas ${ }^{1,3}$, \\ Vasileios Patsiogiannis ${ }^{1,3}$, Charlotte Allan ${ }^{1,4}$, Ben Field ${ }^{1,2}$, James Clark ${ }^{1}$, \\ Felipe Pazos Casal ${ }^{1}$, Ajay Pankhania ${ }^{1}$, Thomas Loosemore ${ }^{1,3}$, and Christian Heiss ${ }^{1,2}$ \\ 1 Surrey and Sussex Healthcare NHS Trust, Redhill, UK \\ 2 Section of Clinical Medicine, Department of Clinical and Experimental Medicine, University of Surrey, Guildford, UK \\ 3 St George's University Hospitals NHS Foundation Trust, London, UK \\ ${ }^{4}$ Brighton and Sussex University Hospitals NHS Trust, Brighton, UK \\ ${ }^{5}$ First Community Health and Care, Redhill, UK
}

\begin{abstract}
Summary: Background: Peripheral artery disease presents an increasing healthcare burden worldwide. Day-case angioplasty in a secondary care setting can be a safe and effective means of meeting the growing demand for lower limb revascularisation. We evaluated the safety and efficacy of a day-case-based angioplasty service in a UK district general hospital. Patients and methods: Consecutive patients undergoing endovascular revascularisation between August 2018 February 2020 were analysed retrospectively. All patients were discussed at a multi-disciplinary (diabetic foot) team meeting following a day case algorithm. Patient and procedural characteristics, technical success, peri-procedural complications, and 30-day outcome of day-case angioplasties were compared with those requiring overnight stay or were hospitalized. Results: Fifty-seven percent of 138 patients were diabetic, mean age $75 \pm 12$ years, 95\% had critical limb ischaemia (Fontaine III $12 \%$, IV 83\%), and baseline ankle brachial pressure index [ABPI] $0.40 \pm 0.30$. Sixty-three patients (45\%) were treated as planned day cases, 21 (15\%) required overnight admission for social indications. Fifteen (11\%) were planned admissions with the need for sequential debridement procedures, and 39 (28\%) were already hospitalised at the time of referral to the vascular service. The overall technical success was $92 \%$ and not successful procedures mainly occurred in patients $>80$ years. The ABPI increased at the initial follow-up to $0.84 \pm 0.18$. Fifty-three percent required treatment of $>1$ level, $80 \%$ included recanalisations of chronic total occlusions, and average total lesion length was $133 \pm 90 \mathrm{~mm}$. Closure devices were employed in all cases. There were no major peri-procedural complications. A single minor access-site related bleeding episode $(0.8 \%)$ occurred, requiring $24 \mathrm{~h}$ observation in hospital. While significantly more wounds had closed in out-patients, the mortality, major amputation and target lesion revascularization did not differ between groups. Conclusions: Safe and effective day-case-based angioplasty can be provided in a secondary care setting for patients with critical limb ischaemia needing complex multi-level procedures.
\end{abstract}

Keywords: Day-case angioplasty, critical limb ischaemia, peripheral artery disease, multi-disciplinary

\section{Introduction}

Peripheral artery disease (PAD) is a growing medical problem worldwide [1], and may affect as many as 1 in 14 people in First-World countries. It represents a major, expanding healthcare burden, as the prevalence of PAD increases with age, affecting more than $25 \%$ of patients older than 65 years in primary care. In its severest form the level of blood flow reaching the limb is inadequate for baseline metabolism with patients suffering rest pain and tissue loss. A rapid response to a diagnosis of critical limb ischaemia (CLI) is crucial to prevent further tissue loss and save limbs [2].

The annual incidence of CLI among PAD patients is estimated at $1-2 \%$ [3]. This is associated with a 1-year risk of mortality/major amputation of between 20\% (rest pain) and $40 \%$ (minor tissue loss), even in patients in whom the foot was salvageable at the time of presentation [4]. The diabetes mellitus epidemic poses a significant challenge with over $50 \%$ of diabetic foot infections presenting in patients with evidence of PAD [5].

Reconstructive arterial surgery in multi-morbid, often elderly patients carries significant risks and these inherent challenges have been a major driver of centralisation of vascular to tertiary care providers [6], particularly in the UK. Day case endovascular intervention is well established [7] but is it safe to perform in secondary-care institutions without surgical assistance readily available? Vascular Networks have evolved around nominated tertiary centers, but it is not clear that the increasing demand for tertiarylevel care can be met if it were deemed necessary for angioplasty to be delivered in a central "hub" location.

Overall endovascular revascularisation is inherently less invasive than surgery, cheaper and associated with lower peri-procedural complication rates with similar or better amputation free survival [8-10]. However more repeat procedures may be required. Several authors have 
documented effectiveness of ambulatory-care endovascular interventions [11-15], including proximal [16] and distal interventions [17], although there tends to be a predominance of non-CLI patients described. The lack of requirement for sedation or general anesthesia results in shorter procedure times performed by a small specialist team. Recovery is rapid and in general more procedures can be performed per operator. Importantly, an "angio-first" policy rarely precludes surgical options. However, requirements for day-case based angioplasties have not been generally agreed. We suggest that a safe secondary-care approach to treating CLI should be "day-case-based", with the assumption for discharge home or to a specific non-vascular surgical ward. Low complication rates need to be a prerequisite, as if post-operative complications would occur and transfer to tertiary vascular hub may be required for these patients. According to the current literature, there may be large variation in complication rates. Complications/unforeseen factors have required "conversion to admission" rates of up to $16 \%$ [18]. Reviews of ambulatory care published work report complications at up to $20 \%[12,18,19]$.

Our unit's standard operating procedure has been designed specifically to deliver a "safe, effective and responsive" day-case-based endovascular revascularisation service. We report our experience in the first 18 months of implementation in a secondary-care hospital - avoiding the need for sending the majority of our predominantly frail CLI patients to distant tertiary care.

\section{Patients and methods}

We performed a single-center retrospective all-comers analysis of all consecutive patients undergoing lower limb endovascular revascularisation from August 2018-February 2020 at East Surrey Hospital, Redhill, UK. The hospital is a secondary care district general hospital supported by the vascular hubs at Brighton and Sussex Medical School and St. George's University Hospital NHS Foundation Trust in London with vascular surgeons and interventional radiologists on joint appointments. We compared patient and procedural characteristics, technical success, peri-procedural complications, 30 day wound healing, mortality, major amputations, and target lesion revascularizations of angioplasties performed in patients as (a) day cases, (b) overnight stay (for social reasons but fulfilling day case criteria), (c) planned hospitalisation for combined intervention (debridement and minor amputations), or (d) already hospitalised patients.

All patients were presented and discussed at our weekly multi-disciplinary team (vascular surgery, angiology, interventional radiology in attendance) or multi-disciplinary diabetic foot team (vascular surgery, angiology, diabetology, microbiology, podiatry, tissue viability in attendance) meetings. The diagnosis of PAD was based on ankle brachial pressure index $(\mathrm{ABPI})<0.9$ with concordant Doppler waveforms and the classification into clinical stages made according to Fontaine: Fontaine II for claudication without rest pain or tissue loss and Fontaine III or IV when rest pain or ischaemic ulcers/gangrene were present and plausibly related to ischaemia. Critical limb ischaemia (CLI) was defined as Fontaine III and IV. In case of incompressible ABPI (>1.2), discordance with Doppler waveform or borderline values that appeared implausible compared to clincal picture, toe-brachial index (TBI) was performed if possible $[20,21]$. Indications for revascularisations were based on current PAD treatment guidelines [20, 21] and included symptomatic PAD such as short distance life-style limiting claudication not responding to or amenable to exercise therapy, rest pain, non-healing ulcer or gangrene. Individualized optimal revascularization modality (angioplasty vs open surgery), surgical risk, technical feasibility and procedure planning was assessed by the team's interventionalists and vascular surgeons based on clinical characteristics, symptoms and imaging including Duplex ultrasound and CT angiogram $(n=103)$.

Patients were accepted for "day case"-based endovascular intervention following a pre-assessment. Inclusion criteria were body mass index $<35 \mathrm{~kg} / \mathrm{m}^{2}$, ASA $<\mathrm{IV}$, eGFR $>29 \mathrm{ml} / \mathrm{min}$, sheath $\leq 7 \mathrm{~F}$ needed for procedure, not socially isolated with $<1 \mathrm{~h}$ drive to hospital, telephone available with responsible adult present overnight, and no anti-coagulation requiring bridging. In individual cases, patients with lower eGFR or higher ASA were accepted with special arrangements. When patients fulfilling all medical criteria but were not able to arrange for a responsible adult to stay with them over night or requested to stay in, we admitted the patients "overnight". If the pre- or postprocedural risk was deemed high by interventionalists or open revascularization required, then patients were referred to be treated at vascular hubs. Metformin was paused $24 \mathrm{~h}$ prior to procedure. Warfarin was paused to reach a target INR $<1.5$. DOACs were paused for $48 \mathrm{~h}$ prior to procedure and restarted on the next day. Aspirin and clopidogrel were not paused.

All procedures were performed by an experienced consultant vascular physician or interventional radiologists according to current treatment guidelines aiming at establishing at least single vessel straight line flow to the foot. In case of crural artery disease, preference was given to the artery supplying the angiosome in which the ulcer or gangrene was present. All patients received a Duplex ultrasound scan of the access sites on the table by the interventionalist and punctures are mostly performed under ultrasound guidance aiming at a common femoral artery puncture site over the mid third of the femoral head. Technical success was defined as the visually successful treatment of the target lesion(s) with less than 30\% remaining stenosis.

Post-procedure, unless there was a contra-indication, patients were started on dual antiplatelet therapy consisting of Aspirin $75 \mathrm{mg}$ and Clopidogrel $75 \mathrm{mg}$ for 1-3 months with a clopidogrel loading dose of $300 \mathrm{mg}$. In case of oral anti-coagulation, we added only clopidogrel. If possible, vascular occlusion devices were used (Angioseal, St Jude Medical, Minnesota). Strict fasting status was not required, 
patients were allowed a small breakfast up to $3 \mathrm{~h}$ before the procedure. A procedure finishing time was set at 14:00 to allow sufficient observation time in the day case unit prior to discharge from hospital or to ward. Patients lay flat for $1 \mathrm{~h}$ followed by $1 \mathrm{~h}$ of bed rest with elevated head, followed by a light snack and drink if desired and discharge after groin check at $4 \mathrm{~h}$. If access was difficult or there was superficial bleeding visible through the transparent dressing, a Duplex ultrasound was performed to exclude haematoma or pseudo-aneurysm. All patients were scheduled within a month of discharge for a Duplex ultrasound examination of the access site and intervened vessel segment together with ABPI and vascular clinic review. Wound care continued throughout within our network or local podiatry. Finally, we recorded wound closure, mortality, major amputation or target lesion revascularization within 30 days following angioplasty.

\section{Statistical analyses}

Data are presented as mean and standard deviation. Mean values were compared using one-way ANOVA and if $\mathrm{p}<0.05$ consecutive Bonferroni post-hoc between group comparison. Non-parametric data were compared with Mann Whitney U-Test. Categorical parameters were compared with Kruskal-Wallis tests. Wound closure, mortality, major amputation or target lesion revascularization within 30 days following angioplasty were assessed with KaplanMeier survival analysis and Log Rank (Mantel-Cox) test. Analyses were performed with SPSS 27 (IBM).

\section{Baseline characteristics}

Baseline characteristics are detailed in Table I. A total of 138 patients (age $75 \pm 12$ years; 70\% > 70 years; 57\% diabetes mellitus; 87\% ASA $\geq$ III) underwent endovascular lower limb arterial procedures. The majority of treated patients had critical limb ischaemia (Fontaine III and IV $95 \%)$ with a baseline ABPI of $0.40 \pm 0.28$. Ulcers were known for $117 \pm 135$ days. A total of $n=63$ (45\%) were treated as planned day cases and $n=21(15 \%)$ were admitted overnight for social reasons, usually no responsible adult at home. Within the treated in-patients, $\mathrm{n}=15$ (11\%) were planned admissions combined with other interventions (minor amputation or debridement) and $\mathrm{n}=39$ (28\%) were patients already hospitalised following emergency department admission.

Day case patients were significantly younger than inpatients, had higher haemoglobin, lower leucocytes, C-reactive protein, and LDL cholesterol as compared to hospitalized patients. There were no significant differences between the groups in terms of co-morbidities and medications. Of note a large proportion of people were not on guideline recommended optimal medical management consisting of platelet inhibitor, statin, and angiotensin converting enzyme inhibitor/angiotensin receptor blockers before angioplasty. Overall, it took on average $18 \pm 16$ days from the multidisciplinary decision to perform the procedure until it was performed with significantly shorter time in hospitalized patients.

\section{Procedural results and outcomes}

Procedural characteristics are detailed in Table II. Most procedures were performed through $6 \mathrm{~F}$ sheaths via antegrade ultrasound guided punctures of the common femoral artery. There was no significant difference between groups for average fluoroscopy time $(1,222 \pm 986 \mathrm{~s})$ or contrast volume $(87 \pm 38 \mathrm{ml})$. The majority of procedures performed were complex, $80 \%$ involving recanalisations of chronic total occlusions, $133 \pm 90 \mathrm{~mm}$ average total lesion length, $63 \%$ of lesions graded as moderately to severely calcified, $53 \%$ treatment of $>1$ level $(1.7 \pm 0.9$ vascular segments [iliac, femoral, popliteal, or crural]), and $51 \%$ requiring stenting $(125 \pm 95 \mathrm{~mm})$. At the end of the procedures, all patients received Angioseal occlusion devices.

The overall technical success rate was 92\% (127/138). Interestingly, we observed that the technical success was age-dependent with the majority of technical failure in patients $>80$ years $(<70$ years: $95 \%$ [39/41]; 70-79 years: $97 \%$ [35/36]; > 80 years: $87 \%$ [53/61]). The 11 not successful cases were discussed between vascular surgeons and interventionalists to decide on further treatment options. Six were due to massively calcified long occlusions of all crural vessels without surgical options and were treated conservatively. Four were related to failure to reentry in massively calcified femoropopliteal occlusions of which 3 were scheduled for a second attempt while 1 was treated conservatively without surgical options.

There were no major peri-procedural complications. In 3 patients, additional manual compression was necessary to achieve complete hemostasis after occlusion device placement. One minor access site related bleeding (0.8\%) occurred during the procedure leading to $24 \mathrm{~h}$ observation in hospital.

At the first follow-up within 1 month no pseudoaneurysms, haematoma, or arteriovenous fistulae were detected on duplex ultrasound. The ABPI increased in $92 \%$ of patients with technically successful procedures to $0.83 \pm 0.19$ (average increase $0.39 \pm 0.30$ ) and there was no difference between the 4 groups $(p<0.001$ pre vs post; $p=0.237$ for interaction with group on 2-way ANOVA).

We then analyzed the wound healing, mortality, major amputations and target lesion revascularization within 30 days after interventions (Table III). While significantly more wounds had closed in Fontaine IV patients in the day case and overnight group, there were no significant difference with regard to mortality, major amputation and target lesion revascularization between the groups.

\section{Discussion}

Our data add to a growing body of evidence that demonstrates the potential for even complex revascularisations 
Table I. Clinical and demographic characteristics of patient population

\begin{tabular}{|c|c|c|c|c|c|}
\hline & Day case & Overnight & Planned hospitalisation & Already hospitalised & $\mathrm{p}$ \\
\hline$n(\%)$ & $63(45 \%)$ & $21(15 \%)$ & $15(11 \%)$ & $39(28 \%)$ & \\
\hline Age (years) & $71 \pm 12$ & $80 \pm 11 *$ & $77 \pm 12^{\star}$ & $78 \pm 11 *$ & 0.005 \\
\hline Haemoglobin (mg/dL) & $128 \pm 18$ & $123 \pm 18$ & $113 \pm 26^{\star}$ & $113 \pm 17 *$ & 0.001 \\
\hline Leucocytes (/dL) & $8.7 \pm 3.1$ & $7.8 \pm 1.8$ & $9.2 \pm 2.6$ & $10.8 \pm 5.0^{*}$ & 0.015 \\
\hline Platelets (/dL) & $280 \pm 106$ & $274 \pm 60$ & $329 \pm 87 *$ & $389 \pm 181 *$ & 0.001 \\
\hline Estimated glomerular filtration rate $(\mathrm{ml} / \mathrm{min})$ & $58 \pm 17$ & $58 \pm 21$ & $53 \pm 24$ & $54 \pm 20$ & 0.594 \\
\hline Total cholesterol (mg/dl) & $4.0 \pm 0.9$ & $3.4 \pm 0.9 *$ & $4.1 \pm 1.1$ & $3.4 \pm 1.3^{*}$ & 0.036 \\
\hline Low-density lipoprotein cholesterol (mg/dL) & $1.8 \pm 0.8$ & $1.4 \pm 0.8$ & $2.0 \pm 1.0$ & $2.4 \pm 1.0 *$ & 0.006 \\
\hline High-density lipoprotein cholesterol (mg/dL) & $1.4 \pm 0.5$ & $1.4 \pm 0.3$ & $1.6 \pm 0.5$ & $1.6 \pm 0.5$ & 0.708 \\
\hline Triglycerides (mg/dL) & $1.7 \pm 1.0$ & $1.4 \pm 0.9$ & $1.2 \pm 0.5$ & $1.4 \pm 0.7$ & 0.188 \\
\hline C-reactive protein (mg/dL) & $29 \pm 33$ & $17 \pm 18$ & $48 \pm 51 *$ & $51 \pm 46^{*}$ & 0.033 \\
\hline International normalized ratio & $1.1 \pm 0.2$ & $1.3 \pm 0.6$ & $1.6 \pm 0.9 *$ & $1.2 \pm 0.2$ & 0.001 \\
\hline Activated partial thromboplastin time (s) & $32 \pm 9$ & $32 \pm 5$ & $41 \pm 15^{\star}$ & $34 \pm 4$ & 0.014 \\
\hline Systolic blood pressure (mmHg) & $155 \pm 18$ & $127 \pm 26$ & $152 \pm 21$ & $152 \pm 21$ & 0.084 \\
\hline Diastolic blood pressure $(\mathrm{mmHg})$ & $82 \pm 9$ & $80 \pm 9$ & $85 \pm 9$ & $84 \pm 12$ & 0.573 \\
\hline Fontaine II (n) & $10(16 \%)$ & $2(10 \%)$ & & & \\
\hline Fontaine III (n) & $10(16 \%)$ & & & $1(3 \%)$ & \\
\hline Fontaine IV (n) & $43(68 \%)$ & $19(90 \%) *$ & $15(100 \%) *$ & $38(97 \%) *$ & $<0.001$ \\
\hline Baseline ankle brachial pressure index & $0.40 \pm 0.26$ & $0.45 \pm 0.29$ & $0.39 \pm 0.32$ & $0.39 \pm 0.32$ & 0.734 \\
\hline Baseline toe brachial index & $0.34 \pm 0.11$ & $0.23 \pm 0.14$ & $0.21 \pm 0.02$ & $0.36 \pm 0.11$ & 0.176 \\
\hline Ulcer known since $(d)$ & $132 \pm 169$ & $117 \pm 113$ & $102 \pm 111$ & $104 \pm 108$ & 0.850 \\
\hline Diabetes mellitus (n) & $33(55 \%)$ & $10(50 \%)$ & 7 (54\%) & $28(74 \%)$ & 0.207 \\
\hline Type 1 (n) & 5 & 1 & 1 & 3 & \\
\hline Type 2 (n) & 28 & 9 & 6 & 25 & \\
\hline Chronic kidney disease (n) & $31(61 \%)$ & $10(56 \%)$ & $7(50 \%)$ & $20(56 \%)$ & 0.892 \\
\hline Arterial hypertension (n) & $42(76 \%)$ & $20(95 \%)$ & $12(86 \%)$ & $30(83 \%)$ & 0.117 \\
\hline Coronary artery disease (n) & $21(40 \%)$ & $12(63 \%)$ & $6(43 \%)$ & $15(43 \%)$ & 0.385 \\
\hline Chronic heart failure (n) & $9(18 \%)$ & $5(26 \%)$ & $3(21 \%)$ & $8(23 \%)$ & 0.864 \\
\hline Stroke $(n)$ & $7(13 \%)$ & $1(6 \%)$ & $2(14 \%)$ & $3(8 \%)$ & 0.745 \\
\hline Cancer (n) & $7(13 \%)$ & 0 & $2(14 \%)$ & $2(6 \%)$ & 0.277 \\
\hline Chronic lung disease (n) & $13(24 \%)$ & $1(5 \%)$ & $3(21 \%)$ & $8(22 \%)$ & 0.363 \\
\hline Atrial fibrillation (n) & $13(22 \%)$ & $4(20 \%)$ & $5(36 \%)$ & $13(37 \%)$ & 0.316 \\
\hline Smoker $(n)$ & $9(17 \%)$ & $1(6 \%)$ & $1(8 \%)$ & $4(13 \%)$ & 0.472 \\
\hline Ex-Smoker (n) & $42(81 \%)$ & $14(88 \%)$ & $8(68 \%)$ & $25(81 \%)$ & \\
\hline ASA $(\%[I I / I I I / I V])$ & $17 / 83 / 0$ & $14 / 80 / 5$ & $13 / 87 / 0$ & $5 / 87 / 8$ & \\
\hline Oral anticoagulation (n) & $15(25 \%)$ & $25(25 \%)$ & $20(43 \%)$ & $14(39 \%)$ & 0.248 \\
\hline Warfarin (n) & $8(13 \%)$ & $4(20 \%)$ & $4(29 \%)$ & $4(11 \%)$ & \\
\hline Rivaroxaban (n) & $3(5 \%)$ & 0 & 0 & $5(14 \%)$ & \\
\hline Apixaban (n) & $4(7 \%)$ & $1(5 \%)$ & $2(14 \%)$ & $5(14 \%)$ & \\
\hline Metformin (n) & $16(27 \%)$ & $5(25 \%)$ & $3(21 \%)$ & $13(35 \%)$ & 0.729 \\
\hline Insulin (n) & $17(30 \%)$ & $6(30 \%)$ & $4(29 \%)$ & $12(33 \%)$ & 0.982 \\
\hline Aspirin (n) & $24(48 \%)$ & $11(58 \%)$ & $4(29 \%)$ & $13(37 \%)$ & 0.284 \\
\hline Clopidogrel (n) & $19(38 \%)$ & $7(37 \%)$ & $4(29 \%)$ & $14(40 \%)$ & 0.903 \\
\hline Statin $(n)$ & $28(56 \%)$ & $15(79 \%)$ & $7(50 \%)$ & $17(49 \%)$ & 0.172 \\
\hline $\begin{array}{l}\text { Angiotensin-converting enzyme } \\
\text { inhibitor/Angiotensin receptor blocker (n) }\end{array}$ & $28(61 \%)$ & $15(83 \%)$ & $7(15 \%)$ & $22(63 \%)$ & 0.234 \\
\hline Beta blocker (n) & $19(42 \%)$ & $7(39 \%)$ & $7(50 \%)$ & $10(29 \%)$ & 0.478 \\
\hline Calcium channel blocker (n) & $11(24 \%)$ & $7(39 \%)$ & $2(14 \%)$ & $6(17 \%)$ & 0.280 \\
\hline
\end{tabular}

Values are mean and standard deviation (percent of total); $p$ value is from one-way ANOVA or Kruskal Wallis test.

*Designates significant difference from day case group.

in patients with multiple co-morbidities $(87 \% \geq$ ASA III) to be performed in a safe and timely manner in a secondary care setting. Previous reports have predominantly featured patients with fewer co-morbidities, with a majority of patients having non-CLI and within tertiary care settings. Akopian et al. describe 112 interventions with a $4 \%$ complication rate and $8 \%$ conversion to admission [11] - all patients were claudicants and little bettered in 
Table II. Procedural characteristics

\begin{tabular}{|c|c|c|c|c|c|}
\hline & $\begin{array}{l}\text { Day } \\
\text { case }\end{array}$ & Overnight & $\begin{array}{c}\text { Planned } \\
\text { hospitalisation }\end{array}$ & $\begin{array}{c}\text { Already } \\
\text { hospitalised }\end{array}$ & $\mathrm{p}$ \\
\hline Iliac (n) & $12(19 \%)$ & $2(10 \%)$ & 0 & $5(13 \%)$ & \\
\hline Femoral (n) & $38(60 \%)$ & $10(48)$ & $9(60 \%)$ & $22(56 \%)$ & \\
\hline Popliteal (n) & $24(38 \%)$ & $8(38 \%)$ & $6(40 \%)$ & $6(15 \%)$ & \\
\hline Crural (n) & $27(43 \%)$ & $13(62 \%)$ & $11(73 \%)$ & $23(59 \%)$ & \\
\hline Multi-level treatment $(n)$ & $35(66 \%)$ & $14(67 \%)$ & $8(53 \%)$ & $16(41 \%)$ & \\
\hline Number treated levels ( $n$ ) & $1.7 \pm 0.8$ & $1.6 \pm 0.9$ & $1.7 \pm 1.0$ & $1.6 \pm 1.0$ & 0.873 \\
\hline Recanalisation ( $\mathrm{n}$ ) & $53(84 \%)$ & $16(76 \%)$ & $14(93 \%)$ & $28(72 \%)$ & 0.297 \\
\hline Total lesion length $(\mathrm{mm})$ & $130 \pm 91$ & $137 \pm 88$ & $130 \pm 74$ & $137 \pm 100$ & 0.982 \\
\hline Lesion calcification (\% [mild/moderate/severe]) & $8 / 36 / 27$ & $14 / 33 / 19$ & $13 / 27 / 27$ & 13/33/18 & \\
\hline Both limbs treated $(n)$ & $3(4.8 \%)$ & $1(4.8 \%)$ & $1(6.7 \%)$ & $1(2.6 \%)$ & \\
\hline Sheath size (n [4F/5F/6F/7F]) & 0/7/56/0 & $0 / 6 / 14 / 1$ & $1 / 3 / 11 / 0$ & $3 / 7 / 29 / 0$ & \\
\hline Common femoral artery access antegrade (n) & $47(75 \%)$ & $15(71 \%)$ & $13(87 \%)$ & $29(74 \%)$ & \\
\hline Common femoral artery access retrograde (n) & $16(25 \%)$ & $6(29 \%)$ & $2(13 \%)$ & $10(26 \%)$ & \\
\hline Pedal access (n) & $2(3 \%)$ & $1(5 \%)$ & $1(7 \%)$ & $2(5 \%)$ & \\
\hline Stenting (n patients) & $33(52 \%)$ & $10(48 \%)$ & $7(47 \%)$ & $21(54 \%)$ & 0.946 \\
\hline Bare metal stents ( $n$ implanted) & 33 & 9 & 5 & 20 & \\
\hline Drug eluting stents ( $\mathrm{n}$ implanted) & 20 & 5 & 7 & 11 & \\
\hline Total stent length $(\mathrm{mm})$ & $121 \pm 97$ & $108 \pm 47$ & $150 \pm 133$ & $131 \pm 99$ & 0.825 \\
\hline Drug coated balloons (n patients) & $17(27 \%)$ & $2(14 \%)$ & $2(13 \%)$ & $4(15 \%)$ & 0.141 \\
\hline Drug coated balloons ( $\mathrm{n}$ implanted) & 63 & 21 & 15 & 39 & \\
\hline Total length drug-coated balloon (mm) & $175 \pm 115$ & $60 \pm 28$ & $80 \pm 0$ & $155 \pm 62$ & 0.369 \\
\hline Fluoroscopy time (s) & $1,183 \pm 894$ & $1,104 \pm 921$ & $1,663 \pm 1,290$ & $1,171 \pm 1,028$ & 0.324 \\
\hline Contrast volume $(\mathrm{mL})$ & $84 \pm 34$ & $91 \pm 44$ & $83 \pm 50$ & $90 \pm 36$ & 0.849 \\
\hline Technical success ( $n$ ) & $61(97 \%)$ & $19(91 \%)$ & $11(73 \%)$ & $36(92 \%)$ & 0.028 \\
\hline Post procedure ankle brachial pressure index & $0.87 \pm 0.19$ & $0.81 \pm 0.21$ & $0.73 \pm 0.20$ & $0.82 \pm 0.18$ & 0.191 \\
\hline Delta ankle brachial pressure index (post-baseline) & $0.42 \pm 0.29$ & $0.21 \pm 0.16$ & $0.48 \pm 0.32$ & $0.38 \pm 0.30$ & 0.082 \\
\hline $\begin{array}{l}\text { Increased ankle brachial pressure index } \\
\text { (\% [increased/unchanged/decreased]) }\end{array}$ & $96 / 2 / 2$ & $93 / 7 / 0$ & $90 / 10 / 0$ & $83 / 10 / 7$ & \\
\hline Occlusion system (n patients) & $63(100 \%)$ & $21(100 \%)$ & $15(100 \%)$ & $39(100 \%)$ & \\
\hline Procedure related complication ( $\mathrm{n}$ ) & $1(2.6 \%)$ & 0 & 0 & 0 & \\
\hline Spurious aneurysm (n) & 0 & 0 & 0 & 0 & \\
\hline AV fistula $(n)$ & 0 & 0 & 0 & 0 & \\
\hline Hematoma (n) & 1 & 0 & 0 & 0 & \\
\hline Life threatening $(n)$ & 0 & 0 & 0 & 0 & \\
\hline Time to angioplasty (d) & $24 \pm 25$ & $23 \pm 17$ & $5 \pm 7 *$ & $8 \pm 8^{\star}$ & $<0.001$ \\
\hline Length of stay (d) & 0 & $1.0 \pm 0.2$ & $25 \pm 25^{*}$ & $54 \pm 27 *$ & $<0.001$ \\
\hline
\end{tabular}

Values are mean and standard deviation (percent of total); $p$ value is from one-way ANOVA or Kruskal Wallis test.

*Designates significant difference from day case group.

Table III. 30-day outcome

\begin{tabular}{|c|c|c|c|c|c|}
\hline & $\begin{array}{l}\text { Day } \\
\text { case }\end{array}$ & Overnight & $\begin{array}{c}\text { Planned } \\
\text { hospitalisation }\end{array}$ & $\begin{array}{c}\text { Already } \\
\text { hospitalised }\end{array}$ & $\mathrm{p}$ \\
\hline 30 day Wound healing $(n)$ & $2(4.7 \%)$ & $3(14.3 \%)$ & 0 & 0 & 0.030 \\
\hline 30 day Mortality (n) & $2(3.2 \%)$ & $1(4.8 \%)$ & $2(13.3 \%)$ & $2(5.1 \%)$ & 0.577 \\
\hline \multirow[t]{2}{*}{$\begin{array}{l}\text { Cause of death } \\
\text { (days after angioplasty) }\end{array}$} & Pneumonia (d 17) & $\begin{array}{l}\text { Cardiogenic } \\
\text { shock (d 25) }\end{array}$ & Sepsis (d 29) & Sepsis (d 11) & \\
\hline & Viral pneumonia/COVID (d 14) & & Sepsis (d 12) & Heart failure (d 7) & \\
\hline 30 day Amputation (n) & $1(1.6 \%)$ & 0 & 0 & 0 & 0.728 \\
\hline 30 day Target lesion revascularisation (n) & $1(1.6 \%)$ & 0 & $1(6.6 \%)$ & $1(2.6 \%)$ & 0.639 \\
\hline
\end{tabular}

Values number of cases with respective endpoint (percent of total for wound healing refers to Fontaine 4 only, and for mortality, major amputation and revascularization all patients); $p$ value is from log-Rank (Mantel-Cox) test.

larger series reported by Maurel et al of non-critical cases [18]. Spiliopoulos et al. used similar criteria for inclusion in their much larger series of day-case procedures [13]
(25\% CLI) requiring $5 \%$ conversion to admission, but a low complication rate of just over $1 \%$ similar to ours. Zayed et al.'s series of 66 patients remains to our knowledge the 
only published series of day-case interventions for predominant CLI [22], albeit within a tertiary-care setting.

In our series, technical success of revascularisation, in a group mostly suffering CLI, was $92 \%$ with a low complication rate $(0.8 \%)$, comparable with the best reported series $[13,18,19,23]$. Our data also support previous studies showing that severe calcifications and extensive disease in old patients due to impossibility to cross lesions may limit technical success [24]. Our data suggest that complication rates can be low even in these complex multi-morbid cases. Although there was a trend for the more complex cases to occur in inpatient settings, the maintenance of a "day-case" approach we believe maintained the low level of complications. There is a predominance of access-related complications in reported series [12, 18, 19]; a uniform deployment of closure devices and ultrasound guided punctures in this series may explain our low incidence of bleeding complications, although the issue remains controversial [25-27].

Close involvement of an interventionist physician/ angiologist from clinic to angio-suite may be another reason why consistent, good results were achieved in our series [28]. The implications of our findings may differ depending on specific interventionalist practice, which varies widely around the world. In the United Kingdom, the centralisation of vascular services to tertiary "hubs" [6] necessitates that procedures performed in secondary care have a low complication rate due to surgical "cover" being severely limited. Besides the fact that coronary procedures are routinely performed in secondary care setting without cardiac surgery cover, there are international parallels related to peripheral angioplasties: a recent series from Southern California describes safe provision of angioplasty in a "rural area" predicated upon lack of an on-site vascular surgeon, among other factors [29]. By adopting strict inclusion criteria only one patient in our series required transfer to a tertiary care setting for an extended period of observation, a figure we think acceptable to a central hub providing that cover. Our approach eases the capacity pressure on the central hub and avoids extensive travel for frail patients.

As the selection of patients amenable for day-case angioplasty is an important determinant of both success and safety, patient assessment and risk stratification are critical for further development of day case procedures. Inclusion criteria applied in published studies show significant variation around common themes such as ASA grade, degree of renal failure and obesity and have formed the basis for previously published recommendations [30, 31]. The development of valid risk assessment tools/scores is an important medical need as it is critical to accommodate the growing number of patients with CLI that are currently not treated in a sufficient and timely manner $[4,32]$ and will be a focus of our future work.

Despite a wider trend for "office-based" vascular interventions [33], in some countries such as Germany angioplasties are seldomly performed as day cases. This is probably partly driven by the reimbursement arrangements for healthcare providers. In our UK cohort, reimbursement could be enhanced by billing for so-called "excluded devices" such as stents and drug-coated balloons, required in a significant proportion of cases. In particular when comparing the income and length of stay of hospitalized patients, day case angioplasty could free up important healthcare resources, reducing bed days and in-hospital complications. Also, while not a specific focus of our study, timely angioplasties hold the potential to prevent emergency department admissions with consequent hospital stays and burden on the healthcare system.

\section{Limitations}

While this is a single-center retrospective observational study, the patient data included reflect an all-comers cohort including all patients receiving angioplasties over the time frame at our institution thereby reflecting real world data. The results may not necessarily translate to other institutions in particular in the UK as our multidisciplinary team is quite unique. The analysis was intended to identify strengths and weaknesses of our service in order to improve it. While the safety and efficacy need to be compared with a representative cohort of patients with best standard of care setting within a tertiary setting to be able to draw valid conclusion, our analysis showed that the safety and efficacy of procedures was very good. However, the analysis also identified areas of improvement. For instance, that the ulcers were known for a long time (117 \pm 135 days average) and the time from decision to performance of angioplasties was 23-24 days for day casebased patients and 5-8 days for in patients. In response to this and to improve earlier detection and treatment we have started to engage more with referring podiatrists, expand our multidisciplinary foot team clinics and introduce a traffic light system for rapid angioplasty scheduling.

\section{Conclusions}

Our data suggest that day case-based angioplasty allows safe and effective treatment even for multi-morbid patients with CLI. Complex, multi-level procedures can be performed without the need to transfer to tertiary care in the vast majority of cases.

\section{References}

1. Song P, Rudan D, Zhu Y, Fowkes FJI, Rahimi K, Fowkes FGR, et al. Global, regional, and national prevalence and risk factors for peripheral artery disease in 2015: an updated systematic review and analysis. Lancet Glob Health. 2019;7(8):e1020-e30.

2. Ireland VSoGBa. Peripheral Arterial Disease - Quality Improvement Framework. 2019.

3. Nehler MR, Duval S, Diao L, Annex BH, Hiatt WR, Rogers K, et al. Epidemiology of peripheral arterial disease and critical limb ischemia in an insured national population. J Vasc Surg. 2014;60(3):686-95.e2

4. Reinecke $H$, Unrath $M$, Freisinger E, Bunzemeier $H$, Meyborg M, Luders F, et al. Peripheral arterial disease and critical limb 
ischaemia: still poor outcomes and lack of guideline adherence. Eur Heart J. 2015;36(15):932-8.

5. Prompers L, Huijberts M, Apelqvist J, Jude E, Piaggesi A, Bakker K, et al. High prevalence of ischaemia, infection and serious comorbidity in patients with diabetic foot disease in Europe. Baseline results from the Eurodiale study. Diabetologia. 2007;50(1):18-25.

6. Ireland TVSoGBa. The Provision of Services for Patients with Vascular Disease. 2019.

7. Lemarbre L, Hudon G, Coche G, Bourassa MG. Outpatient peripheral angioplasty: survey of complications and patients' perceptions. AJR Am J Roentgenol. 1987;148(6):1239-42.

8. Bradbury AW, Adam DJ, Bell J, Forbes JF, Fowkes FG, Gillespie I, et al. Bypass versus Angioplasty in Severe Ischaemia of the Leg (BASIL) trial: An intention-to-treat analysis of amputation-free and overall survival in patients randomized to a bypass surgeryfirst or a balloon angioplasty-first revascularization strategy. J Vasc Surg. 2010;51(5 Suppl):5s-17 s.

9. Lin JH, Brunson A, Romano PS, Mell MW, Humphries MD. Endovascular-first treatment is associated with improved amputation-free survival in patients with critical limb ischemia. Circ Cardiovasc Qual Outcomes. 2019;12(8):e005273.

10. Tsai TT, Rehring TF, Rogers RK, Shetterly SM, Wagner NM, Gupta R, et al. The contemporary safety and effectiveness of lower extremity bypass surgery and peripheral endovascular interventions in the treatment of symptomatic peripheral arterial disease. Circulation. 2015;132(21):1999-2011.

11. Akopian G, Katz SG. Peripheral angioplasty with same-day discharge in patients with intermittent claudication. J Vasc Surg. 2006;44(1):115-8.

12. Albert B, Davaine JM, Chaillet MP, Grimandi G, Guyomarch B, Azéma L, et al. Clinical and economic evaluation of ambulatory endovascular treatment of peripheral arterial occlusive lesions. Ann Vasc Surg. 2014;28(1):137-43.

13. Spiliopoulos S, Karnabatidis D, Katsanos K, Diamantopoulos A, Ali T, Kitrou P, et al. Day-case treatment of peripheral arterial disease: results from a multi-center European study. Cardiovasc Intervent Radiol. 2016;39(12):1684-91.

14. Vernet FBM, Hartung O, Dona B, Alimi Y. Ambulatory Arterial Endovascular Treatment (AAET): Prospective evaluation of safety and effectiveness. 30th Annual Meeting French Society for Vascular Surgery. 2015.

15. Malekzadeh S, Rolf T, Doenz F, Chouiter A, Jouannic AM, Qanadli SD. Safety of elective percutaneous peripheral revascularization in outpatients: A 10-year single-center experience. Diagn Interv Imaging. 2019;100(6):347-52.

16. Miller C, Frood R, See TC, Hammond CJ. British Society of Interventional Radiology lliac Angioplasty and Stent Registry: fourth report on an additional 8,294 procedures. Clin Radiol. 2019;74(6):429-34.

17. D'Souza SM, Stout CL, Krol E, Dexter DJ, Ahanchi SS, Panneton JM. Outpatient endovascular tibial artery intervention in an office-based setting is as safe and effective as in a hospital setting. J Endovasc Ther. 2018;25(6):666-72.

18. Maurel B, Paumier A, Jacobi D, Bleuet F, Martinez R, Lermusiaux P. Ambulatory percutaneous angioplasty in patients with claudication. Ann Vasc Surg. 2011;25(2):191-6.

19. Gouicem D, Palcau L, Le Hello C, Cameliere L, Dufranc J, Coffin $\mathrm{O}$, et al. Feasibility of ambulatory percutaneous femoral access without the use of arterial closure systems. Ann Vasc Surg. 2014;28(1):132-6.

20. Frank U, Nikol S, Belch J, Boc V, Brodmann M, Carpentier $\mathrm{PH}$, et al. European society of vascular medicine: Guideline on peripheral arterial disease. VASA. 2019;48(Suppl. 102): $1-79$.

21. Conte MS, Bradbury AW, Kolh P, White JV, Dick F, Fitridge R, et al. Global vascular guidelines on the management of chronic limb-threatening ischemia. Eur J Vasc Endovasc Surg. 2019;58(1S):S1-S109 e33.

22. Zayed HA, Fassiadis N, Jones KG, Edmondson RD, Edmonds $\mathrm{ME}$, Evans DR, et al. Day-case angioplasty in diabetic patients with critical ischemia. Int Angiol. 2008;27(3):232-8.
23. Kasthuri R, Karunaratne D, Andrew H, Sumner J, Chalmers N. Day-case peripheral angioplasty using nurse-led admission, discharge, and follow-up procedures: arterial closure devices are not necessary. Clin Radiol. 2007;62(12):1202-5.

24. Janas A, Milewski K, Buszman PP, Janas K, Blachut A, Pruski $M$, et al. Safety and feasibility of same-day early discharge after endovascular revascularization of lower extremities in elderly. SENIOR-ER registry. Catheter Cardiovasc Interv. 2018;91(3):515-20.

25. Cox T, Blair L, Huntington C, Lincourt A, Sing R, Heniford BT. Systematic review of randomized controlled trials comparing manual compression to vascular closure devices for diagnostic and therapeutic arterial procedures. Surg Technol Int. 2015;27:32-44.

26. Robertson L, Andras A, Colgan F, Jackson R. Vascular closure devices for femoral arterial puncture site haemostasis. Cochrane Database Syst Rev. 2016;3:Cd009541.

27. Stegemann E, Busch L, Stegemann B, Lauer T, Hoffmann R, Heiss C, et al. Evaluation of a structured training program for arterial femoral sheath removal after percutaneous arterial catheter procedures by assistant personnel. Am J Cardiol. 2015;115(7):879-83.

28. Heiss C, Madaric J, Belch J, Brodmann M, Mazzolai L. The compelling arguments for the need of medical vascular physicians in Europe. Vasa. 2019;48(6):487-91.

29. Ansari A, Shah MA, Shah MA, Ansari Z. Safety of day-case endovascular interventions for peripheral arterial disease in a rural, underserved area. Ther Adv Cardiovasc Dis. 2020; 14:1753944720948651.

30. Alimi Y, Hauguel A, Casbas L, Magnan PE, Pin JL, Sabatier J, et al. French guidelines for the management of ambulatory endovascular procedures for lower extremity peripheral artery disease. Ann Vasc Surg. 2019;59:248-58.

31. Hauguel A, Maurel B, Bague N, Gouaillier-Vulcain F, Costargent A, Chaillou P, et al. Management of ambulatory (day case) endovascular procedures for peripheral arterial disease. J Cardiovasc Surg (Torino). 2017;58(2):293-304.

32. Stella J, Engelbertz C, Gebauer K, Hassu J, Meyborg M, Freisinger E, et al. Outcome of patients with chronic limbthreatening ischemia with and without revascularization. Vasa. 2020;49(2):121-7.

33. Jones WS, Mi X, Qualls LG, Vemulapalli S, Peterson ED, Patel $\mathrm{MR}$, et al. Trends in settings for peripheral vascular intervention and the effect of changes in the outpatient prospective payment system. J Am Coll Cardiol. 2015;65(9):920-7.

\section{History}

Submitted: 14.10.2020

Accepted after revision: 01.02.2021

Published online: 18.02.2021

\section{Acknowledgement}

We thank Andrew Turner for provision of reimbursement data and critical review of the manuscript and Ciara Giltinan and Ali Nehghan-Nayeri for helping to gather outcome data as part of their final year undergraduate project at the University of Surrey.

\section{Conflicts of interests}

No conflicts of interest exist.

\section{Correspondence address}

Prof. Dr. Christian Heiss

Clinical Medicine Section

Department of Clinical and Experimental Medicine

Faculty of Health and Medical Sciences

University of Surrey

Stag Hill

Guildford GU2 7XH

United Kingdom

c.heiss@surrey.ac.uk 